\title{
Early pH Change Predicts Intensive Care Unit Mortality
}

\author{
Sujay Samanta, Ratender Kumar Singh, Arvind K Baronia, Prabhaker Mishra, Banani Poddar, Afzal Azim, Mohan Gurjar \\ Department of Critical Care Medicine, Sanjay Gandhi Postgraduate Institute of Medical Sciences, Lucknow, Uttar Pradesh, India
}

\section{Abstract}

\begin{abstract}
Aim of the Study: Metabolic acidosis is associated with increased mortality in critically ill patients. We hypothesized that early correction of acidosis of presumed metabolic origin results in improved outcomes. Patients and Methods: We conducted a prospective, observational study from February 2015 to June 2016 in a 12 bed mixed intensive care unit (ICU) of a 1000 bed tertiary care hospital in the north of India. ICU patients aged above 18 years with an admission $\mathrm{pH} \geq 7.0$ to $<7.35$ of presumed metabolic origin were included. Arterial blood gas parameters including $\mathrm{pH}, \mathrm{PaO}_{2}, \mathrm{PaCO}_{2}, \mathrm{HCO}_{3}^{-}, \mathrm{Na}^{+}, \mathrm{K}^{+}, \mathrm{Cl}^{-}$, anion gap (AG), base excess, and lactate at 0,6 , and $24 \mathrm{~h}$ along with other standard laboratory investigations were recorded. The primary outcome was to assess the impact of early pH changes on mortality at day 28 of ICU. Results: A total of 104 patients with $60.6 \%$ males and $91.3 \%$ medical patients were included in the study. Sepsis of lung origin $(60.6 \%)$ was the predominant etiology. By day 28, 68 (65.4\%) patients had died. Median age was 49.5 years, weight $61.7 \mathrm{~kg}$, Sequential Organ Failure Assessment, and Acute Physiologic and Chronic Health Evaluation II scores were 16 and 12, respectively. Nonsurvivors had a higher vasopressor index $(P<0.01)$, lactate and central venous oxygen saturation $(P<0.05)$, and lower $\mathrm{pH}(P<0.05)$. A pH correction/change of $\geq 1.16 \%$ during the first $24 \mathrm{~h}$ had the best receiver operating characteristic for predicting survival at day 28 , with area under the curve (95\% confidence interval, 0.72 [0.62-0.82], $P<0.05)$ compared to $\mathrm{HCO}_{3}^{-}$, BE, lactate, and AG. Conclusions: Metabolic acidosis is associated with higher mortality in ICU. The rate of change in $\mathrm{pH}$ may better predict ICU mortality than other metabolic indices.
\end{abstract}

Keywords: Metabolic acidosis, mortality, $\mathrm{pH}$ change

\section{INTRODUCTION}

Metabolic acidosis is a challenging acid-base disorder, especially in the critically ill. ${ }^{[1,2]}$ It can result from an increase in the concentration of hydrogen $\left(\mathrm{H}^{+}\right)$ions or a decrease in bicarbonate $\left(\mathrm{HCO}_{3}^{-}\right)$ions, respectively. Various etiologies of metabolic acidosis include sepsis, cardiogenic shock, severe hypoxemia, hepatic failure, and intoxication. Metabolic acidosis can be classified as high or normal anion gap (AG) acidosis. ${ }^{[3,4]}$ Lactic acidosis is a common cause of high AG metabolic acidosis..$^{[5-8]}$ It is further classified as Type-A (anaerobic) and Type-B (aerobic). Type-A lactic acidosis is associated with tissue hypoperfusion with inadequate oxygen delivery although with intact mitochondrial function. In Type-B lactic acidosis, there is an adequate cellular oxygen supply, no tissue hypoxia, and acidosis occurs due to abnormal carbohydrate metabolism, as in hepatic failure, diabetes, or phenformin intoxication. ${ }^{[9,10]}$ The development of lactic acidosis depends on the magnitude of lactate elevation, the buffering capacity of the body, and coexistence of other conditions producing tachypnea and alkalosis (e.g., liver

\begin{tabular}{|l|l|}
\hline \multicolumn{3}{|c|}{ Access this article online } \\
\hline Quick Response Code: & Website: \\
\hline & www.ijccm.org \\
\cline { 2 - 2 } & \\
\hline
\end{tabular}

disease, sepsis). Thus, hyperlactatemia may be associated with a normal $\mathrm{pH}$, acidemia, or alkalemia.

Metabolic acidosis is often caused by hyperlactatemia in critically ill patients. ${ }^{[3,11,12]}$ Severe academia in sepsis contributes to hemodynamic instability owing to reduced myocardial contractility, arterial vasodilation, and impaired catecholamine responsiveness. In severe acidemia (blood $\mathrm{pH}<7.1$ ), these effects can result in organ dysfunction and contribute to increased morbidity and mortality. Irrespective of the etiology, metabolic acidosis is associated with increased mortality in critically ill patients. ${ }^{[1,11,13,14]}$ Survivors of severe sepsis and septic shock had better acidosis resolution than nonsurvivors. ${ }^{[1]}$

Address for correspondence: Dr. Ratender Kumar Singh, Department of Critical Care Medicine, Sanjay Gandhi Postgraduate Institute of Medical Sciences, Raebareli Road, Lucknow - 226014 , Uttar Pradesh, India E-mail: ratenderrks70@gmail.com

This is an open access journal, and articles are distributed under the terms of the Creative Commons Attribution-NonCommercial-ShareAlike 4.0 License, which allows others to remix, tweak, and build upon the work non-commercially, as long as appropriate credit is given and the new creations are licensed under the identical terms.

For reprints contact: reprints@medknow.com

How to cite this article: Samanta S, Singh RK, Baronia AK, Mishra P, Poddar B, Azim A, et al. Early pH change predicts intensive care unit mortality. Indian J Crit Care Med 2018;22:697-705. 
Enough supportive evidence exists to suggest that early lactate clearance is associated with reduced mortality and morbidity. ${ }^{[3,15-17]}$ However, the same, though believed, cannot yet be claimed about early $\mathrm{pH}$ correction. We hypothesized that early hour clearance of metabolic acidosis, of either septic or nonseptic origin, is associated with improved outcomes. We proposed to do this prospective observational study to assess the effect of early hour $\mathrm{pH}$ changes on mortality in critically ill patients.

\section{Patients and Methods}

\section{Ethics and consent}

After prior approval from the institute's ethics committee and written informed consent from patients or their first of kin, we conducted the present prospective observational study. The study period was from February 2015 to June 2016. A 12 bed mixed intensive care unit (ICU) of a tertiary care referral hospital and academic institute in the north of India was utilized for this purpose.

\section{Inclusion criteria}

Critically ill ICU patients aged 18 years or above, with an admission $\mathrm{pH} \geq 7.0$ but $<7.35$, and presumed to be of metabolic origin were included in the study.

\section{Exclusion criteria}

Patient with a $\mathrm{pH}<7.0$, acidosis presumed to be respiratory origin, age below 18 years, and refusal of consent were excluded from the study.

\section{Definitions}

Acidosis

Acidosis was defined as an arterial $\mathrm{pH}$ of $<7.35$. It was arbitrarily considered corrected if the arterial $\mathrm{pH}$ was $>7.35$. Acidosis was further categorized as metabolic, respiratory, or mixed. Metabolic acidosis was defined as a state of decreased systemic $\mathrm{pH}$, resulting from either a primary increase in $\mathrm{H}^{+}$or a decrease in $\mathrm{HCO}_{3}^{-}$blood concentration. ${ }^{[18]}$

\section{Hemodynamics}

Hemodynamic status during the first $24 \mathrm{~h}$ was defined by the vasopressor index..$^{[19-21]}$ We modified the vasopressor index to include vasopressin in place of phenylephrine as vasopressin is the most commonly used vasopressor after noradrenaline in septic shock. This was calculated as per the formula $(($ Dopamine dose $\times 1)+($ Dobutamine dose $\times 1)$ $+($ Adrenaline dose $\times 100)+($ Noradrenaline dose $\times 100)+$ (Vasopressin dose $\times 10$ )].

All doses were in $\mu \mathrm{g} / \mathrm{kg} / \mathrm{min}$, except vasopressin which was in units/hour.

\section{Study protocol}

Following admission to our ICU, consecutive patients satisfying the inclusion criteria were included in the study. Our observations and analysis were disclosed to the ICU treating team. However, any alteration in clinical management based on our analysis was entirely at their discretion. Arterial blood gas (ABG) analysis with lactate was measured at 0,6 , and $24 \mathrm{~h}$ on the day of admission. All patients were followed until day 28 of ICU stay or discharge or death whichever occurred earlier for measurement of outcomes.

\section{Measurements}

Arterial blood samples were obtained from the existing invasive hemodynamic intra-arterial catheter (either radial or femoral artery) or through direct arterial puncture in case the intra-arterial catheter was yet not inserted. The ABG samples were used for determination of $\mathrm{pH}, \mathrm{PaO}_{2}, \mathrm{PaCO}_{2}, \mathrm{HCO}_{3}^{-}, \mathrm{Na}^{+}$, $\mathrm{K}^{+}, \mathrm{Cl}^{-}, \mathrm{AG}$, base excess (BE), and lactate at 0,6 , and $24 \mathrm{~h}$ by automated blood gas analyzer. Also determined simultaneously were serum lactate from the same ABG sample and central venous oxygen saturation $\left(\mathrm{ScVO}_{2}\right)$ from venous blood from the central vein catheter. Additional ABG samples, biochemistry, and other investigations were obtained whenever required as per the judgment of the attending ICU physician.

\section{Arterial blood gas machine}

ABG analysis was performed on Cobas b 221 system (Roche Diagnostics GmbH, Mannheim, Germany) with the integrated AutoQC drawer option and electrodes for $\mathrm{pH}, \mathrm{PO}_{2}$, $\mathrm{PCO}_{2}$, reference electrode, and an ion selective electrode measuring sodium, potassium, and chloride. Specimens were analyzed using our standard operating procedure which included preanalytical protocols (such as safety, temperature, and transportation time) by trained authorized laboratory technicians, with automated internal quality control. External quality controls were performed at least 4 times a year with samples. Two milliliter nonheparinized syringes were used for collection of the arterial samples. These samples were then immediately transported at room temperature to the ABG machine housed within a minutes walking distance from our ICU.

\section{Data collection}

Demographic (age, gender, type of patient/admission, category of illness, etc.), clinicophysiologic characteristics (coexisting illness, organ failure, hemodynamic, and respiratory status), biochemical characteristics ( $\mathrm{Hb} \%$, complete blood count, serum electrolytes, renal and liver function test, random blood glucose, and procalcitonin [PCT], etc.), ICU severity scores (Acute Physiologic and Chronic Health Evaluation-II [APACHE-II] and Sequential Organ Failure Assessment [SOFA]) were all recorded. $\mathrm{ABG}$ indices, lactate, and $\mathrm{ScVO}_{2}$ were also determined as previously mentioned. Organ supportive interventions such as fluid therapy, blood and blood product transfusions, sodium bicarbonate administration, vasoactive agents, vasopressor index, mechanical ventilation (MV), and renal replacement therapy (RRT) were also documented. Outcomes such as mortality, length of MV, and length of ICU/Hospital stay were recorded until 28 days of ICU stay or discharge or death whichever occurred earlier.

\section{Sample size}

Sample size was calculated assuming a proportion of $\mathrm{pH}$ change ( $\geq 0.10$ ) equal to 0.50 in survivors and 0.20 in 
nonsurvivors at a minimum of $80 \%$ power of study and $95 \%$ confidence interval. Minimum sample size of 65 in survivors and 34 in nonsurvivors was needed to detect a difference in group proportions of 0.30 . Sample size was calculated using software power analysis and sample size (NCSS[2008] PASS, Kaysville, UT).

\section{Statistical analysis}

Normality of continuous data was tested using Shapiro-Wilk test. Nonnormal, continuous data were expressed as median (interquartile range), while categorical data were expressed as frequency and percentage. Mann-Whitney U-test was used to compare the medians between survivors and nonsurvivors. Receiver operating characteristic (ROC) curve was drawn to predict survival at day 28 of ICU stay. Chi-square test was used to compare the proportions/test the association between groups. For repeated observations over time, Friedman analysis of variance (ANOVA) was used to estimate the significance level among the time points. If in Friedman ANOVA, the $P$ value was observed to be significant then the difference in medians between individual groups was further assessed using the Wilcoxon Signed Rank test. A two-tailed $P<0.05$ was considered statistically significant. IBM, SPSS version 23 (SPSS Inc., Chicago IL, USA) was used for statistical analysis.

\section{RESULTS}

\section{Baseline characteristics}

A total of 104 patients, 63 males (60.6\%) and 95 (91.3\%) medical patients were included in the study. The nature of illness for which these patients got admitted to our ICU was mainly respiratory $(33 / 104,31.7 \%)$. Sepsis of lung origin (63/104, $60.6 \%$ ) was the predominant etiology. Most of the patients studied had already received prior ICU care $(91 / 104,87.5 \%)$, MV (75/104, 72.1\%), and RRT (14/104, 13.5\%) before this admission. Half of those who had previously undergone RRT also received it within the first $24 \mathrm{~h}$ of our ICU admission. A little over half $(55 / 104,52.9 \%)$ of the patients in the study did not have any coexisting illness. By day 28 of ICU stay, $68(65.4 \%)$ patients succumbed to their illness. Thirteen of the $36(12.5 \%)$ who survived were discharged home directly from the ICU. Nonsurvivors did not differ significantly from survivors, except for prior ICU care $(P=0.02)$. Baseline characteristics of patients and their comparison between survivors and nonsurvivors were as depicted in Table 1.

\section{Physiochemical characteristics}

Nonsurvivors had significantly greater tachycardia $(120.5$ [113-125] vs. 112 [105-122] in survivors; $P<0.001)$, tachypnea (31 [27-33] vs. 26 [(24.2-30.7] in survivors; $P<0.001)$, and vasopressor index (32 [20.2-61.5] vs. $8.5[(0-22.5]$ in survivors; $P<0.001)$. Oxygenation $\left(\mathrm{PaO}_{2} / \mathrm{FiO}_{2}\right.$ ratio $)$ and positive end-expiratory pressure at 0,6 , and $24 \mathrm{~h}$ were comparable. No significant differences in fluid balance or need for blood transfusions were observed at or within $24 \mathrm{~h}$ period of admission, between groups. Among biochemical parameters, coagulation profile (International normalized ratio and activated partial thromboplastin time), blood urea nitrogen (BUN), and PCT were significantly higher in nonsurvivors $(P<0.05)$, while hemoglobin was significantly lower $(P=0.02)$. Electrolyte levels done during the first $24 \mathrm{~h}$ of admission were also comparable. The physiochemical characteristics of the study population were as depicted in Table 2.

\section{Acid-Base characteristics}

Nonsurvivors had significantly higher lactate and $\mathrm{ScVO}_{2}$ at 0,6 , and $24 \mathrm{~h}(P<0.001)$. AG was also significantly higher at 0 and $24 \mathrm{~h}(P<0.05)$; $\mathrm{pH}$ was significantly lower at $24 \mathrm{~h}$ in nonsurvivors. Trends over time were significantly unidirectional for most parameters, except for AG. Significant change in metabolic profile was observed for all parameters at $\Delta 0-24 \mathrm{~h}$, except $\mathrm{ScVO}_{2}$ in survivors. However, the changes were insignificantly minimal at $\Delta 0-6 \mathrm{~h}$, except for lactate (nonsurvivors; $P<0.001$ ), $\mathrm{pH}$ (survivors; $P=0.04$ ), and $\mathrm{ScVO}_{2}$ (nonsurvivors; $P=0.01$ ). In the middle period of $\Delta 6-24 \mathrm{~h}$, the majority of the parameters differed significantly [Table 3$]$.

\section{Hyperlactatemia}

Hyperlactatemia ( $\geq 18 \mathrm{mg} / \mathrm{dL})$ was observed in half $(n=52)$ of the patients. The majority of these patients $(42 / 52$, $80.8 \%$ ) did not survive, as compared to those with normal levels $(26 / 52,50 \% ; P=0.002)$. Survivors among patients with normal lactate had lower lactate levels compared to nonsurvivors at 0,6 , and $24 \mathrm{~h}$. However, lactate profiles were comparable between groups in patients with hyperlactatemia. A larger proportion of patients had $\geq 3$ organ failures in the group with hyperlactatemia $(P=0.036)$. They also had significantly higher APACHE-II, SOFA, vasopressor index, AG, PCT, and $24 \mathrm{~h}$ fluid balance. Furthermore, these patients had lower $24 \mathrm{~h} \mathrm{pH}$ and poorer liver function and coagulation profile [Table 4].

\section{Outcomes}

Nonsurvivors had significantly higher APACHE-II and SOFA scores $(P<0.001)$. They also had a significantly longer median time interval between the onset of illness and admission to our ICU (9 [6-12] vs. 8 [5-11.7] in survivors; $P=0.01)$. They, however, had a shorter ICU stay (7 [4-14.5] vs. $16.5[7.2-27.7]$ in survivors; $P<0.01)$. Sixty of the $68(88 \%)$ nonsurvivors had three or more organ failures at ICU admission $(P<0.001)$. Two $(34 / 104,32.7 \%)$ and three $(59 / 104,56.7 \%)$ organ failures occurred at admission. Three or more organ failures $(60 / 68,88 \%)$ occurred more commonly in nonsurvivors $(P<0.001)$. A higher proportion of nonsurvivors (61.8\%) required one or more RRT sessions within the first $24 \mathrm{~h}$ of ICU admission, although this was not statistically significant. The outcome-related characteristics of the study population were as depicted in Table 5 .

\section{Survival prediction}

Among all $\mathrm{ABG}$ parameters, $\mathrm{pH}$ was significantly higher in survivors. $\mathrm{pH}$ correction/delta change $\geq 1.16 \%$ during the 


\begin{tabular}{|c|c|c|c|c|}
\hline Characteristics & All $(n=104)$ & Survivors $(n=36)$ & Nonsurvivors $(n=68)$ & $P$ \\
\hline Age, years & $49.5(32.2-62)$ & $48(29.2-59.5)$ & $49.5(35-65)$ & 0.30 \\
\hline Weight, kg & $61.7(56.6-66)$ & $62(56.9-65.7)$ & $60.5(56.6-66)$ & 0.93 \\
\hline Male/female, $n$ & $63 / 41$ & $24 / 12$ & $39 / 29$ & 0.35 \\
\hline \multicolumn{5}{|c|}{ Category of patients, $n(\%)$} \\
\hline Medical & $95(91.3)$ & $33(91.7)$ & $62(91.2)$ & 0.93 \\
\hline Surgical & $9(8.7)$ & $3(8.3)$ & $6(8.8)$ & \\
\hline \multicolumn{5}{|l|}{ Prior therapy, $n(\%)$} \\
\hline ICU & $91(87.5)$ & $28(77.8)$ & $63(92.6)$ & $0.02 *$ \\
\hline RRT & $14(13.5)$ & $4(11.1)$ & $10(14.7)$ & 0.60 \\
\hline MV & $75(72.1)$ & $24(66.7)$ & $51(75)$ & 0.36 \\
\hline \multicolumn{5}{|c|}{ Nature of illness, $n(\%)$} \\
\hline Cardiac & $5(4.8)$ & $2(5.5)$ & $3(4.4)$ & 0.66 \\
\hline Respiratory & $33(31.7)$ & $8(22.2)$ & $25(36.8)$ & \\
\hline Neurological & $9(8.7)$ & $5(13.8)$ & $4(5.9)$ & \\
\hline Gastrointestinal & $5(4.8)$ & $3(8.3)$ & $2(2.9)$ & \\
\hline Hepatic & $15(14.4)$ & $5(13.9)$ & $10(14.7)$ & \\
\hline SAP & $15(14.4)$ & $6(16.7)$ & $9(13.2)$ & \\
\hline Sepsis & $15(14.4)$ & $4(11.1)$ & $11(16.2)$ & \\
\hline Tropical & $3(2.9)$ & $1(2.8)$ & $2(2.9)$ & \\
\hline Others & $4(3.8)$ & $2(5.6)$ & $2(2.9)$ & \\
\hline \multicolumn{5}{|c|}{ Source of admission, $n(\%)$} \\
\hline Emergency & $33(31.7)$ & $10(27.8)$ & $23(33.8)$ & 0.33 \\
\hline ICU interhospital & $39(37.5)$ & $14(38.9)$ & $25(36.8)$ & \\
\hline ICU intrahospital & $24(23.1)$ & $7(19.4)$ & $17(25)$ & \\
\hline Ward intrahospital & $8(7.7)$ & $5(13.9)$ & $3(4.4)$ & \\
\hline \multicolumn{5}{|l|}{ Comorbidities, $n(\%)$} \\
\hline Diabetes & $6(5.8)$ & $3(8.3)$ & $3(4.4)$ & 0.82 \\
\hline Hypertension & $8(7.7)$ & $3(8.3)$ & $5(7.3)$ & \\
\hline Hypothyroid & $2(1.9)$ & 0 & $2(2.9)$ & \\
\hline COPD & $5(4.8)$ & $1(2.8)$ & $4(5.9)$ & \\
\hline CAD & $4(3.8)$ & $1(2.8)$ & $3(4.4)$ & \\
\hline CKD & $5(4.8)$ & $3(8.3)$ & $2(2.9)$ & \\
\hline CLD & $7(6.7)$ & $1(2.8)$ & $6(8.8)$ & \\
\hline Diabetes and HTN & $4(3.8)$ & $1(2.8)$ & $3(4.4)$ & \\
\hline Multiple ( $\geq 3$ ) & $4(3.8)$ & $1(2.8)$ & $3(4.4)$ & \\
\hline Other & $4(3.8)$ & $2(5.6)$ & $2(2.9)$ & \\
\hline Nil & $55(52.9)$ & $20(55.5)$ & $35(51.5)$ & \\
\hline \multicolumn{5}{|l|}{ Septic foci, $n(\%)$} \\
\hline Respiratory & $63(60.6)$ & $17(47.2)$ & $46(67.6)$ & 0.10 \\
\hline Abdominal & $30(28.8)$ & $12(33.3)$ & $18(26.5)$ & \\
\hline Neurological & $6(5.8)$ & $4(11.1)$ & $2(2.9)$ & \\
\hline Urinary & $2(1.9)$ & $1(2.8)$ & $1(1.5)$ & \\
\hline Hematological & $1(1)$ & 0 & $1(1.5)$ & \\
\hline Unknown & $2(1.9)$ & $2(5.5)$ & 0 & \\
\hline
\end{tabular}

All measurements are in median (interquartile range) unless specified. ${ }^{*} P<0.05$. ICU: Intensive care unit; RRT: Renal replacement therapy; MV: Mechanical ventilation; SAP: Severe acute pancreatitis; COPD: Chronic obstructive pulmonary disease; CAD: Coronary artery disease; CKD: Chronic kidney disease; CLD: Chronic liver disease; HTN: Hypertension

first $24 \mathrm{~h}$ had the best ROC, predicting survival at day 28 , with area under the curve (AUC) $(95 \%$ [confidence interval], $0.72[0.62-0.82] ; P<0.001)$ with sensitivity and specificity of $77 \%$ and $61 \%$, respectively. Delta change of other ABG parameters such as $\mathrm{HCO}_{3}^{-}$, BE, lactate, and $\mathrm{AG}$ over first $24 \mathrm{~h}$ had lower AUC of ROC for predicting survival at day 28 [Table 6].

\section{Discussion}

The diagnosis and management of major acid-base disturbances are standard care aspects in critically ill patients. Metabolic acidosis is commonly encountered in ICU in severe sepsis and septic shock, irrespective of renal function and is often associated with poor outcomes. ${ }^{[1,22,23]}$ Although hyperchloremic acidosis is associated with poor outcomes, studies in ICU 


\begin{tabular}{|c|c|c|c|c|}
\hline Parameters & All $(n=104)$ & Survivors $(n=36)$ & Nonsurvivors $(n=68)$ & $P$ \\
\hline \multicolumn{5}{|l|}{ Physiological } \\
\hline \multicolumn{5}{|l|}{ Hemodynamics } \\
\hline Heart rate/min, $0 \mathrm{~h}$ & $116(110-124)$ & $112(105-122)$ & $120.5(113-125)$ & $<0.01 *$ \\
\hline MAP $<65$ mmHg, 0 h, $n(\%)$ & $81(77.9)$ & $24(23.1)$ & $57(54.8)$ & 0.05 \\
\hline $\mathrm{NE}$, maximum dose in $24 \mathrm{~h}, \mu / \mathrm{kg} / \mathrm{min}$ & $0.22(0.06-0.35)$ & $0.07(0-0.20)$ & $0.25(0.18-0.41)$ & $<0.01^{*}$ \\
\hline Vasopressor index & $23.5(7.2-44.7)$ & $8.5(0-22.5)$ & $32(20.2-61.5)$ & $<0.01^{*}$ \\
\hline Temperature $>38.3^{\circ} \mathrm{C}, 0 \mathrm{~h}, n(\%)$ & $43(41.3)$ & $13(12.5)$ & $30(28.5)$ & 0.53 \\
\hline \multicolumn{5}{|l|}{ Respiratory } \\
\hline Respiratory rate/min, $0 \mathrm{~h}$ & $29(26-32)$ & $26(24.2-30.75)$ & $31(27-33)$ & $<0.01^{*}$ \\
\hline \multicolumn{5}{|l|}{$\mathrm{PaO}_{2} / \mathrm{FiO}_{2}$ ratio } \\
\hline $0 \mathrm{~h}$ & $250(188-300)$ & $250(200-342.5)$ & $240(188-300)$ & 0.41 \\
\hline $6 \mathrm{~h}$ & $280(220-320)$ & $285(250-315)$ & $250(200-320)$ & 0.09 \\
\hline $24 \mathrm{~h}$ & $260(220-320)$ & $250(240-260)$ & $280(200-320)$ & 0.63 \\
\hline PEEP > 12, within 24 h, $n(\%)$ & $19(18.3)$ & $5(4.8)$ & $14(13.5)$ & 0.44 \\
\hline Fluid balance at $24 \mathrm{~h}, \mathrm{~L} /$ day & $1.3(0.6-2.1)$ & $1.2(0.5-2)$ & $1.4(0.9-2.2)$ & 0.17 \\
\hline Blood transfusion, within $24 \mathrm{~h}, n(\%)$ & $13(12.5)$ & $3(2.9)$ & $10(9.6)$ & 0.41 \\
\hline \multicolumn{5}{|l|}{ Chemical } \\
\hline \multicolumn{5}{|l|}{ Renal function } \\
\hline Blood urea nitrogen (mg/dL) & $48(29.2-66)$ & $35.5(26-63.5)$ & $50(33.2-70.2)$ & $0.03 *$ \\
\hline Creatinine $(\mathrm{mg} / \mathrm{dL})$ & $2.3(1.3-3.5)$ & $2.1(1.2-4.1)$ & $2.35(1.6-3.4)$ & 0.49 \\
\hline \multicolumn{5}{|l|}{ Liver function } \\
\hline Total bilirubin & $1.7(0.9-6.3)$ & $1.5(0.6-2.6)$ & $2(1-7.7)$ & $0.04 *$ \\
\hline Total protein & $5.2(4.8-5.8)$ & $5.3(5-5.8)$ & $5.2(4.5-5.8)$ & 0.38 \\
\hline Albumin & $2.7(2.4-3.1)$ & $2.7(2.4-3.1)$ & $2.7(2.4-3.1)$ & 0.75 \\
\hline Aspartate aminotransferase & $88.5(49-153.2)$ & $72(48.5-111.7)$ & $97(49-250.7)$ & 0.14 \\
\hline Alanine aminotransferase & $48.5(23.7-118.7)$ & $44.5(30.7-61)$ & $54(21-157.2)$ & 0.27 \\
\hline Alkaline phosphatase & $119.5(86-176)$ & $112(76.5-176.2)$ & $127(93-176)$ & 0.55 \\
\hline International normalized ratio & $1.32(1.1-1.9)$ & $1.2(1.1-1.4)$ & $1.4(1.2-2.2)$ & $<0.01^{*}$ \\
\hline APTT & $33.05(28-42.8)$ & $30.3(26.5-34.7)$ & $34.4(29.9-52)$ & $<0.01^{*}$ \\
\hline \multicolumn{5}{|l|}{ Hematological } \\
\hline Total leukocyte count $\left(\times 10^{9} / \mathrm{L}\right)$ & $13.7(9.1-20.4)$ & $12.2(9.5-18.3)$ & $14.2(8.7-20.8)$ & 0.48 \\
\hline Platelet count $\left(\times 10^{9} / \mathrm{L}\right)$ & $126.5(87-198.7)$ & $143(101.7-201)$ & $120.5(79-196)$ & 0.30 \\
\hline Hemoglobin $(\mathrm{g} / \mathrm{dL})$ & $10.2(9.3-11.8)$ & $11(9.8-12)$ & $10(9-11)$ & $0.02 *$ \\
\hline Random blood sugar (mg/dL), $0 \mathrm{~h}$ & $189(162.7-217)$ & $198(167-225)$ & $188(159-215)$ & 0.29 \\
\hline Procalcitonin $(\mathrm{ng} / \mathrm{mL})$ & $6.2(2-14.4)$ & $1.7(0.7-6.1)$ & $8.8(3.6-22.4)$ & $<0.01^{*}$ \\
\hline \multicolumn{5}{|l|}{ Electrolytes $(\mathrm{mEq} / \mathrm{L})$} \\
\hline Sodium & $141(135-147)$ & $141(136-148)$ & $141.5(135-147)$ & 0.69 \\
\hline Potassium & $4.0(3.6-4.5)$ & $4.2(3.6-4.5)$ & $4(3.6-4.4)$ & 0.12 \\
\hline Chloride & $106(102-110)$ & $106(104-110)$ & $107(101-110)$ & 0.99 \\
\hline Magnesium & $2.2(2-2.6)$ & $2.2(1.9-2.6)$ & $2.2(2-2.5)$ & 0.97 \\
\hline Phosphate & $4.5(3.3-6)$ & $4.6(3.3-6)$ & $4.4(3.1-6)$ & 0.71 \\
\hline
\end{tabular}

All measurements are in median (IQR) unless specified. ${ }^{*} P<0.05$. MAP: Mean arterial pressure; NE: Norepinephrine; PEEP: Positive end-expiratory pressure; APTT: Activated partial thromboplastin time; IQR: Interquartile range

patients have failed to detect a significant attributable effect on mortality. ${ }^{[1]}$ The main findings of our prospective observational study were as follows: (a) significant physiochemical and acid-base derangements [Tables 2 and 3] contributed to the higher morbidity and mortality in nonsurvivors [Table 5], (b) patients with hyperlactatemia had worse outcomes [Table 4], and (c) changes in $\mathrm{pH}$ had better predictability for ICU survival than other ABG parameters.

\section{Metabolic acidosis and prognosis}

Noritomi et al.$^{[1]}$ in a study of 60 patients with severe sepsis or septic shock, concluded that nonsurvivors exhibited a complex metabolic acidosis at ICU admission. Severity of metabolic acidosis predicts ICU and hospital mortality, ${ }^{[1,11,14,24-27]}$ length of stay, hospital morbidity, ${ }^{[28,29]}$ and transfusion requirements ${ }^{[30]}$ in medical, surgical, or trauma ICU patients. While AG predicts short-term mortality, strong ion gap predicts both short- and long-term mortality, in AKI patients with metabolic acidosis. ${ }^{[31]}$ However, apart from lactate, there is no consensus about the clinical relevance of individual components of metabolic acidosis.

In the present study, we observed that patients with earlier acidosis resolution had lower mortality. The $\mathrm{pH}$, relative to 


\begin{tabular}{|c|c|c|c|c|c|c|c|c|}
\hline \multirow{2}{*}{$\begin{array}{l}\text { Parameters } \\
\text { Median } \\
\text { (IQR) }\end{array}$} & \multirow{2}{*}{$\begin{array}{l}\text { Groups } \\
\text { Survivors }(n=36) \\
\text { Nonsurvivors }(n=68)\end{array}$} & \multicolumn{3}{|c|}{ Timing of measurements $(n=104)$} & \multirow[t]{2}{*}{$P \# \#$} & \multicolumn{3}{|c|}{$P^{\# \# \#}$} \\
\hline & & $\mathrm{Oh}$ & $6 \mathrm{~h}$ & $24 \mathrm{~h}$ & & $\Delta 0-6$ & $\Delta 6-24$ & $\Delta 0-24$ \\
\hline \multirow{3}{*}{$\begin{array}{l}\text { Lactate, } \\
\mathrm{mg} / \mathrm{dl}\end{array}$} & Survivors & $12.0(8.6-18.7)$ & $10.7(9.0-14.1)$ & $10.0(8.0-12.0)$ & $<0.001 * *$ & 0.10 & $0.003 *$ & $0.002 *$ \\
\hline & Nonsurvivors & $20(15.0-34.7)$ & $18.5(14.0-31.7)$ & $18.5(14.0-27.9)$ & $0.001 *$ & $<0.001 *$ & 0.07 & $<0.001 * *$ \\
\hline & $P^{\sharp}$ & $<0.001 *$ & $<0.001 *$ & $<0.001 *$ & & & & \\
\hline \multirow[t]{3}{*}{$\mathrm{pH}$} & Survivors & $7.30(7.23-7.30)$ & $7.32(7.25-7.37)$ & $7.40(7.35-7.42)$ & $<0.001 * *$ & $0.04 *$ & $<0.001 * *$ & $<0.001 * *$ \\
\hline & Nonsurvivors & $7.28(7.24-7.31)$ & $7.28(7.23-7.34)$ & $7.33(7.28-7.39)$ & $<0.001 * *$ & 0.32 & $<0.001 * *$ & $<0.001 * *$ \\
\hline & $P^{\#}$ & 0.87 & 0.05 & $<0.001^{*}$ & & & & \\
\hline \multirow[t]{3}{*}{ Base excess } & Survivors & $7.9(11.3-4.8)$ & $5.9(10.9-4.3)$ & $3.6(6.3-1.0)$ & $<0.001 * *$ & 0.18 & $<0.001 * *$ & $<0.001 * *$ \\
\hline & Nonsurvivors & $8(11.7-5.7)$ & $7.95(12.0-5.0)$ & $4.6(8.8-1.9)$ & $<0.001 * *$ & 0.80 & $<0.001 * *$ & $<0.001^{* *}$ \\
\hline & $P^{\#}$ & 0.50 & 0.09 & 0.07 & & & & \\
\hline \multirow{3}{*}{$\begin{array}{l}\mathrm{HCO}_{3}, \\
\mathrm{mEq} / \mathrm{L}\end{array}$} & Survivors & $18.1(15.6-20.0)$ & $19.2(15.9-21.4)$ & $21.4(18.5-26.0)$ & $<0.001 * *$ & 0.15 & $<0.001 * *$ & $<0.001 * *$ \\
\hline & Nonsurvivors & $18.0(14.2-20.0)$ & $17.5(14.4-20.4)$ & $20.0(17.0-23.0)$ & $<0.001 * *$ & 0.94 & $<0.001 * *$ & $<0.001 * *$ \\
\hline & $P^{\#}$ & 0.78 & 0.18 & 0.05 & & & & \\
\hline \multirow[t]{3}{*}{ Anion gap } & Survivors & $15.0(12.0-18.7)$ & $17.0(14.2-20.0)$ & $13.0(11.2-14.9)$ & $<0.001 * *$ & 0.05 & $<0.001 * *$ & $<0.001 * *$ \\
\hline & Nonsurvivors & $16.0(15.0-22.7)$ & $18.0(14.0-21.7)$ & $16.0(12.7-19.7)$ & 0.10 & 0.07 & 0.09 & $0.003 *$ \\
\hline & $P^{\#}$ & 0.03 & 0.44 & $<0.001 *$ & & & & \\
\hline \multirow[t]{3}{*}{$\mathrm{SCVO}_{2}(\%)$} & Survivors & $66.0(65.0-77.5)$ & $68.0(65.0-77.5)$ & $74.0(65.7-76.7)$ & 0.32 & 0.65 & 0.05 & 0.08 \\
\hline & Nonsurvivors & $76.0(66.25-81.75)$ & $78.0(71.2-83.0)$ & $78.0(73.2-84.7)$ & $0.001 *$ & $0.01 *$ & 0.33 & $0.002 *$ \\
\hline & $P^{\#}$ & 0.01 & $<0.001 *$ & $<0.001 *$ & & & & \\
\hline
\end{tabular}

Statistical tests used for calculating significance: ${ }^{*} P$ : Mann-Whitney U-test; ${ }^{\#} P$ : Friedman ANOVA; ${ }^{\# \#} P$ : Wilcoxon signed ranks test; ${ }^{*} P<0.05 ; * * P<0.001$. IQR: Interquartile range; $\mathrm{SCVO}_{2}$ : Central venous oxygen saturation; $\Delta$ : Delta

other ABG parameters, was significantly higher in survivors. On the other hand, nonsurvivors had higher ICU severity scores (APACHE II and SOFA), higher BUN, PCT, and more deranged coagulation profile and organ failures.

\section{Lactic acidosis and mortality}

Lactic acidosis is a common cause of metabolic acidosis in ICU. Mortality in patients with lactic acidosis, persisting beyond $24 \mathrm{~h}$, approaches $70 \%{ }^{\left[{ }^{[32]}\right.}$ In a prospective observational study of 126 patients admitted emergently with severe sepsis or septic shock, Lee et al. ${ }^{[13]}$ observed that lactic acidosis and not hyperlactatemia, accurately predicted mortality in severe sepsis and septic shock. Noritomi et al..$^{[1]}$ in a study of 60 patients with severe sepsis or septic shock, concluded that in survivors, the resolution of acidosis was attributable to the decrease in strong ion gap and lactate. Furthermore, in another prospective observational study on 111 patients from both emergency and ICU, Nguyen et al. ${ }^{[3]}$ reported that patients with lactate clearance $\geq 10 \%$ had a greater reduction in APACHE II score at $72 \mathrm{~h}$ and also a lower 60 -day mortality $(P=0.007)$, relative to patients with a lactate clearance $<10 \%$. Contrary to this, Marik and Bellomo ${ }^{[16]}$ in his review on lactate suggested that lactate clearance should not be used as the end-point of resuscitation in patients with sepsis. Significant majority of our patients with hyperlactatemia $(42 / 52,80.8 \%)$ did not survive, as compared to those with normal lactate levels $(26 / 52,50 \%$; $P=0.002$ ). Furthermore, survivors with normal lactate had lower levels at 0,6 , and $24 \mathrm{~h}$.

\section{Metabolic acidosis correction}

Early recognition and prompt correction of metabolic acidosis are essential to survival. Treatment of metabolic acidosis is multimodal, involving identification and treatment of the underlying cause with simultaneous appropriate resuscitative and organ supportive measures. Although RRT seems attractive, particularly in patients with renal dysfunction, randomized controlled studies are needed to prove benefits of this strategy in treatment of lactic acidosis. Acidosis resolution in survivors was attributable to a decrease in strong ion gap and lactate. ${ }^{[1]}$ A prospective randomized, double-blind, controlled clinical trial by Chen et al. ${ }^{[33]}$ in 2013 , conducted on 65 critically ill septic shock patients with lactic acidosis, concluded that bicarbonate therapy significantly reduced the incidence of multiple organ dysfunction, duration of $\mathrm{MV}$, ICU and hospital length of stay, and mortality. Kim et al. ${ }^{[34]}$ in 2013 , in a retrospective analysis, reported that septic patients with metabolic acidosis, especially those with high AG, had higher mortality with sodium bicarbonate administration. However, although evidence is minimal, it is usually recommended to treat serum $\mathrm{pH}<7.1$, empirically with sodium bicarbonate, $1 \mathrm{mEq} / \mathrm{Kg}$, unless the underlying acidosis is believed to be immediately responsive to therapy. ${ }^{[35]}$ In a study of chronic hemodialysis patients, correcting metabolic acidosis resulted in improved growth hormone insensitivity, increased and normalized plasma free T3 concentration, and improved plasma albumin ${ }^{[36]}$ A recently published multicenter, open-label, randomized controlled, phase 3 trial, in 26 French ICUs, concluded that in patients with severe metabolic acidemia, sodium bicarbonate infusion did not affect 28-day mortality and presence of at least one organ failure at day 7 . However, 28-day mortality and need for RRT was decreased in a subset of AKI patients. ${ }^{[37]}$ In our study, we used sodium bicarbonate infusion in three patients when the $\mathrm{pH}$ was $<7.10$; 


\begin{tabular}{|c|c|c|c|c|}
\hline Characteristics & All $(n=104)$ & Hyperlactatemia $(n=52)$ & Normal lactate $(n=52)$ & $P$ \\
\hline \multicolumn{5}{|l|}{ Lactate, $\mathrm{mg} / \mathrm{dL}$} \\
\hline $0 \mathrm{~h}$ & $17.7(12.0-30.0)$ & $30(21.2-44.7)$ & $12(9.0-14.7)$ & $<0.001$ \\
\hline $6 \mathrm{~h}$ & $15(12.0-26.8)$ & $25.5(17.2-36.0)$ & $12(9.2-14.0)$ & $<0.001$ \\
\hline $24 \mathrm{~h}$ & $15(10.7-23.7)$ & $22.5(16.0-31.2)$ & $11(8.1-14.0)$ & $<0.001$ \\
\hline Survival, $n(\%)$ & $36(34.6)$ & $10(9.6)$ & $26(25)$ & 0.002 \\
\hline \multicolumn{5}{|l|}{ Severity scores, o/a } \\
\hline APACHE II & $16(12.5-21)$ & $18(15-22)$ & $14(10-18.7)$ & 0.001 \\
\hline SOFA & $12(10-14)$ & $13.5(10-14)$ & $10(7.2-12)$ & $<0.001$ \\
\hline Vasopressor index & $23.5(7.2-44.7)$ & $27(16.5-63.5)$ & $19(0.5-33.5)$ & 0.004 \\
\hline Fluid balance, at $24 \mathrm{~h}, \mathrm{~L} /$ day & $1.3(0.6-2.1)$ & $1.6(1-2.45)$ & $1.05(0.52-1.97)$ & 0.04 \\
\hline \multicolumn{5}{|l|}{ Organ failures o/a, $n(\%)$} \\
\hline One & $4(3.8)$ & $1(1)$ & $3(2.9)$ & 0.04 \\
\hline Two & $34(32.7)$ & $12(11.5)$ & $22(21.2)$ & \\
\hline Three & $59(56.7)$ & $33(31.7)$ & $26(25)$ & \\
\hline Four & $7(6.7)$ & $6(5.8)$ & $1(1)$ & \\
\hline $24 \mathrm{~h} \mathrm{pH}$ & $7.35(7.31-7.40)$ & $7.33(7.28-7.39)$ & $7.40(7.33-7.41)$ & 0.02 \\
\hline \multicolumn{5}{|l|}{ Anion gap } \\
\hline $0 \mathrm{~h}$ & $16(14.2-21)$ & $16(15-23.7)$ & $15(12.2-19)$ & 0.03 \\
\hline $6 \mathrm{~h}$ & $18(14-20.9)$ & $18(15-22)$ & $15(12.5-18.7)$ & 0.01 \\
\hline $24 \mathrm{~h}$ & $14(12-19)$ & $16(13.2-19)$ & $13.5(12-16)$ & 0.01 \\
\hline \multicolumn{5}{|l|}{ Liver function } \\
\hline Total bilirubin, mg/dL & $1.7(0.9-6.3)$ & $3(1-8.2)$ & $1.6(0.8-2.6)$ & 0.03 \\
\hline Total protein, mg/dL & $5.2(4.8-5.8)$ & $5.1(4.5-5.8)$ & $5.4(5-5.9)$ & 0.01 \\
\hline AST, IU/L & $88.5(49-153.2)$ & $96(49.2-408.2)$ & $72(48.2-116.5)$ & 0.04 \\
\hline ALT, IU/L & $48.5(23.7-118.7)$ & $59.5(23-243.7)$ & $42(24-61)$ & 0.03 \\
\hline INR & $1.32(1.1-1.9)$ & $1.5(1.2-2.6)$ & $1.2(1.1-1.4)$ & $<0.001$ \\
\hline APTT, s & $33(28-42.8)$ & $34.4(31.1-52)$ & $30.8(27-36.7)$ & 0.01 \\
\hline Procalcitonin, ng/mL & $6.2(2-14.4)$ & $7.8(2.7-38.1)$ & $5.1(1-10.5)$ & 0.01 \\
\hline
\end{tabular}

only one patient among these survived at day 28. Though our study is an observational study not designed to address the impact of sodium bicarbonate infusion in severe metabolic acidosis, inference from the French ICU study, ${ }^{[37]}$ despite their limitations, is quite meaningful. In real-world scenario, a substantial proportion of AKI patients with metabolic acidosis would receive sodium bicarbonate to either defer or delay a dialysis depending on the acuity of illness. We also did not find any significant difference in fluid balance at $24 \mathrm{~h}$ and need of blood transfusion within 24-h period between survivors and nonsurvivors. Interestingly, RRT support was almost equally distributed in either group. Furthermore, we observed that $\mathrm{pH}$ correction/delta change of $\geq 1.16 \%$ during first $24 \mathrm{~h}$ had the best ROC for predicting survival at day 28 with an AUC of $0.72(0.62-0.82)$ and $P<0.05$, compared to other parameters such as $\mathrm{HCO}_{3}^{-}, \mathrm{BE}$, lactate, and $\mathrm{AG}$.

\section{Limitations}

The several limitations that existed in our study were as follows: (a) single-center study with a small sample size; (b) variability in time of onset of illness and ICU admission, resuscitation, and organ supportive therapy before our admission and the quality of care provided during inter-/intra-hospital transportation may have all influenced the acid-base milieu; (c) presence of mixed acid-base disorders may have affected the $\mathrm{pH}$; (d) multiple factors during our ICU admission such as MV, RRT, fluids, organ dysfunction/ failure, antibiotics and source control, and the timing and intensity of life supportive interventions make it difficult to ascertain the dominating influence; (e) ABG errors during sample withdrawal, collection, transportation, and analysis were not accounted for in the study. Limitations b, c, and d would be difficult to remove and shall continue to influence any $\mathrm{pH}$-based study. Despite the above limitations, ours is a sincere attempt to study the impact of early hour $\mathrm{pH}$ changes on mortality and morbidity in critically ill ICU patients.

\section{Conclusions}

Metabolic acidosis in ICU patients is frequently associated with varied etiologies and poor outcomes. Survivors have better acidosis resolution than nonsurvivors. As compared to lactate and other metabolic indices, early hour $\mathrm{pH}$ correction is a better predictor of ICU survival. However, due to the abovementioned limitations, generalization of our results to other ICU patients' needs to be done cautiously. We further 


\begin{tabular}{|c|c|c|c|c|}
\hline Characteristics & All $(n=104)$ & Survivors $(n=36)$ & Nonsurvivors $(n=68)$ & $P$ \\
\hline \multicolumn{5}{|l|}{ Severity scores, o/a } \\
\hline APACHE II & $16(12.5-21)$ & $13(8.2-15)$ & $18(15-22)$ & $<0.01$ \\
\hline SOFA & $12(10-14)$ & $10(6-11.7)$ & $12(10.2-14)$ & $<0.01$ \\
\hline Duration of illness before current ICU admission, days & $8(5-11.7)$ & $7.5(4.2-10)$ & $9(6-12)$ & 0.01 \\
\hline LOS ICU, days & $9(5-18)$ & $16.5(7.2-27.7)$ & $7(4-14.5)$ & $<0.01$ \\
\hline \multicolumn{5}{|l|}{ Organ failures o/a, $n(\%)$} \\
\hline One & $4(3.8)$ & $4(11.1)$ & 0 & $<0.01$ \\
\hline Two & $34(32.7)$ & $26(72.2)$ & $8(11.8)$ & \\
\hline Three & $59(56.7)$ & $5(13.9)$ & $54(79.4)$ & \\
\hline Four & $7(6.7)$ & $1(2.8)$ & $6(8.8)$ & \\
\hline \multicolumn{5}{|l|}{ RRT within $1^{\text {st }} 24 \mathrm{~h}$} \\
\hline None & $48(46.2)$ & $22(61.1)$ & $26(38.2)$ & 0.54 \\
\hline Once & $53(51)$ & $14(38.9)$ & $39(57.3)$ & \\
\hline Twice & $3(2.9)$ & 0 & $3(4.4)$ & \\
\hline \multicolumn{5}{|l|}{ Overall outcome } \\
\hline Death & $69(63.3)$ & $1(2.8)$ & $68(100)$ & $<0.01$ \\
\hline Discharged home & $13(12.5)$ & $13(36.1)$ & 0 & \\
\hline Transferred to other ICU & $3(2.9)$ & $3(8.3)$ & 0 & \\
\hline Transferred to other ward & $19(18.3)$ & $19(52.8)$ & 0 & \\
\hline
\end{tabular}

All measurements are in median (IQR) unless specified. o/a: On admission; APACHE: Acute Physiology and Chronic Health Evaluation; SOFA: Sequential organ failure assessment; LOS: Length of stay; ICU: Intensive care unit; RRT: Renal replacement therapy; IQR: Interquartile range

Table 6: Delta changes of arterial blood gas parameters over $24 \mathrm{~h}$ predicting survival at day 28

\begin{tabular}{lcccc}
\hline $\boldsymbol{\Delta} \mathbf{0}-\mathbf{2 4}$ & Cutoff (\%) & ROC of AUC (95\% CI) & Sensitivity (\%) & Specificity (\%) \\
\hline $\mathrm{pH}$ & $\geq 1.16$ & $0.72(0.62-0.82)$ & 77 & 61 \\
$\mathrm{HCO}_{3}^{-}$ & $\geq 14.2$ & $0.59(0.48-0.71)$ & 69 & 55 \\
Lactate & $\geq-9.2$ & $0.50(0.38-0.61)$ & 77 & 27 \\
Anion gap & $\geq-1.5$ & $0.52(0.41-0.63)$ & 83 & $0.001^{* *}$ \\
\hline
\end{tabular}

ROC of AUC: Receiver operative characteristics of area under curve; CI: Confidence interval; $\mathrm{HCO}_{3}^{-}$: Bicarbonate ion; $\Delta$ : Delta; ${ }^{* *} P<0.001$

suggest future trials with specific interventions to rectify metabolic acidosis early, before the true impact of $\mathrm{pH}$ change can be used for prognostication in critically ill.

\section{Acknowledgments}

The authors wish to thank the Department of Biostatistics and Health Informatics of the institute for the support provided in statistical analysis of the results.

\section{Financial support and sponsorship \\ Nil.}

\section{Conflicts of interest}

There are no conflicts of interest.

\section{RefEREnCES}

1. Noritomi DT, Soriano FG, Kellum JA, Cappi SB, Biselli PJ, Libório AB, et al. Metabolic acidosis in patients with severe sepsis and septic shock: A longitudinal quantitative study. Crit Care Med 2009;37:2733-9.

2. Gauthier PM, Szerlip HM. Metabolic acidosis in the Intensive Care Unit. Crit Care Clin 2002;18:289-308, vi.

3. Nguyen HB, Rivers EP, Knoblich BP, Jacobsen G, Muzzin A, Ressler JA, et al. Early lactate clearance is associated with improved outcome in severe sepsis and septic shock. Crit Care Med 2004;32:1637-42.

4. Oh MS, Carroll HJ. The anion gap. N Engl J Med 1977;297:814-7.

5. Kraut JA, Kurtz I. Use of base in the treatment of acute severe organic acidosis by nephrologists and critical care physicians: Results of an online survey. Clin Exp Nephrol 2006;10:111-7.

6. Kraut JA, Madias NE. Lactic acidosis. N Engl J Med 2014;371:2309-19.

7. Madias NE. Lactic acidosis. Kidney Int 1986;29:752-74.

8. Stacpoole PW. Lactic acidosis. Endocrinol Metab Clin North Am 1993;22:221-45.

9. Arieff AI. Indications for use of bicarbonate in patients with metabolic acidosis. Br J Anaesth 1991;67:165-77.

10. Hindman BJ. Sodium bicarbonate in the treatment of subtypes of acute lactic acidosis: Physiologic considerations. Anesthesiology 1990;72:1064-76.

11. Gunnerson KJ, Saul M, He S, Kellum JA. Lactate versus non-lactate metabolic acidosis: A retrospective outcome evaluation of critically ill patients. Crit Care 2006;10:R22.

12. Khosravani H, Shahpori R, Stelfox HT, Kirkpatrick AW, Laupland KB. Occurrence and adverse effect on outcome of hyperlactatemia in the critically ill. Crit Care 2009;13:R90.

13. Lee SW, Hong YS, Park DW, Choi SH, Moon SW, Park JS, et al. Lactic acidosis not hyperlactatemia as a predictor of in hospital mortality in septic emergency patients. Emerg Med J 2008;25:659-65.

14. Allyn J, Vandroux D, Jabot J, Brulliard C, Galliot R, Tabatchnik X, et al. Prognosis of patients presenting extreme acidosis $(\mathrm{pH}<7)$ on admission to Intensive Care Unit. J Crit Care 2016;31:243-8.

15. Jansen TC, van Bommel J, Mulder PG, Lima AP, van der Hoven B, Rommes JH, et al. Prognostic value of blood lactate levels: Does the clinical diagnosis at admission matter? J Trauma 2009;66:377-85.

16. Marik PE, Bellomo R. Lactate clearance as a target of therapy in sepsis: A flawed paradigm. OA Crit Care 2013;1:3.

17. Lee YK, Hwang SY, Shin TG, Jo IJ, Suh GY, Jeon K, et al. Prognostic 
value of lactate and central venous oxygen saturation after early resuscitation in sepsis patients. PLoS One 2016;11:e0153305.

18. Seifter JL. Acid-base disorders. In: Goldman L, Schafer AI, editors. Goldman-Cecil Medicine. $25^{\text {th }}$ ed. Elsevier: Philadelphia; 2016. p. 762-74.

19. Wernovsky G, Wypij D, Jonas RA, Mayer JE Jr., Hanley FL, Hickey PR, et al. Postoperative course and hemodynamic profile after the arterial switch operation in neonates and infants. A comparison of low-flow cardiopulmonary bypass and circulatory arrest. Circulation 1995;92:2226-35

20. Zuppa AF, Nadkarni V, Davis L, Adamson PC, Helfaer MA, Elliott MR, et al. The effect of a thyroid hormone infusion on vasopressor support in critically ill children with cessation of neurologic function. Crit Care Med 2004;32:2318-22.

21. Cruz DN, Antonelli M, Fumagalli R, Foltran F, Brienza N, Donati A, et al. Early use of polymyxin B hemoperfusion in abdominal septic shock: The EUPHAS randomized controlled trial. JAMA 2009;301:2445-52.

22. Mecher C, Rackow EC, Astiz ME, Weil MH. Unaccounted for anion in metabolic acidosis during severe sepsis in humans. Crit Care Med 1991;19:705-11.

23. O'Dell E, Tibby SM, Durward A, Murdoch IA. Hyperchloremia is the dominant cause of metabolic acidosis in the postresuscitation phase of pediatric meningococcal sepsis. Crit Care Med 2007;35:2390-4.

24. Kincaid EH, Miller PR, Meredith JW, Rahman N, Chang MC. Elevated arterial base deficit in trauma patients: A marker of impaired oxygen utilization. J Am Coll Surg 1998;187:384-92.

25. Rocktaeschel J, Morimatsu H, Uchino S, Bellomo R. Unmeasured anions in critically ill patients: Can they predict mortality? Crit Care Med 2003;31:2131-6.

26. Husain FA, Martin MJ, Mullenix PS, Steele SR, Elliott DC. Serum lactate and base deficit as predictors of mortality and morbidity. Am J Surg 2003;185:485-91.

27. Randolph LC, Takacs M, Davis KA. Resuscitation in the pediatric trauma population: Admission base deficit remains an important prognostic indicator. J Trauma 2002;53:838-42.

28. Sánchez-Lozada R, Chapa-Azuela O, Gutiérrez-Vega R, Fernández-Hidalgo E. Use of base deficit as a prognosis factor for acute pancreatitis. Gac Med Mex 2003;139:108-11.

29. Piper G, Patel NA, Chandela S, Benckart DH, Young JC, Collela JJ, et al. Short-term predictors and long-term outcome after ruptured abdominal aortic aneurysm repair. Am Surg 2003;69:703-9.

30. Rutherford EJ, Morris JA Jr., Reed GW, Hall KS. Base deficit stratifies mortality and determines therapy. J Trauma 1992;33:417-23.

31. Zheng CM, Liu WC, Zheng JQ, Liao MT, Ma WY, Hung KC, et al. Metabolic acidosis and strong ion gap in critically ill patients with acute kidney injury. Biomed Res Int 2014;2014:819528.

32. Forrest DM, Russell JA. Metabolic acidosis. In: Webb A, Shapiro M, Singer M, Suter P, editors. Oxford Textbook of Critical Care. $1^{\text {st }}$ ed. USA: Oxford University Press; 1999. p. 573-7.

33. Chen XF, Ye JL, Zhu ZY. The use of sodium bicarbonate in stages in treating hypoperfusion induced lactic acidemia in septic shock. Zhonghua Wei Zhong Bing Ji Jiu Yi Xue 2013;25:24-7.

34. Kim HJ, Son YK, An WS. Effect of sodium bicarbonate administration on mortality in patients with lactic acidosis: A retrospective analysis. PLoS One 2013;8:e65283.

35. Kraut JA, Madias NE. Metabolic acidosis: Pathophysiology, diagnosis and management. Nat Rev Nephrol 2010;6:274-85.

36. Wiederkehr MR, Kalogiros J, Krapf R. Correction of metabolic acidosis improves thyroid and growth hormone axes in haemodialysis patients. Nephrol Dial Transplant 2004;19:1190-7.

37. Jaber S, Paugam C, Futier E, Lefrant JY, Lasocki S, Lescot T, et al. Sodium bicarbonate therapy for patients with severe metabolic acidaemia in the Intensive Care Unit (BICAR-ICU): A multicentre, open-label, randomised controlled, phase 3 trial. Lancet 2018;392:31-40. 